\title{
Outcomes of revision surgery for difficult to catheterize continent channels in a multi-
} institutional cohort of adults

\author{
Ronak Ambrish Gor \\ Department of Urology, University of Minnesota, Minneapolis, MN, United States
}

Cite as: Can Urol Assoc J 2017 Dec. 22; Epub ahead of

print. http://dx.doi.org/10.5489/cuaj.4656

Published online December 22, 2017

$* * *$

\section{Abstract}

Introduction: We aimed to describe the strategies of surgical revision for catheterizable channel obstruction and their outcomes, including restenosis and new channel incontinence.

Methods: We retrospectively queried the charts of adults who underwent catheterizable channel revision or replacement from 2000-2014 for stomal stenosis, channel obstruction, or difficulty with catheterization at the Universities of Minnesota, Michigan, and Utah. The primary endpoint was channel patency as measured by freedom from repeat surgical intervention. Secondary endpoints included post-revision incontinence and complication rates. Revision surgeries were classified by strategy into “above fascia," “below fascia,” and “channel replacement” groupings. Results: A total of 51 patients who underwent 68 repairs (age 18-82 years old; mean 45) were identified who met our inclusion criteria. Channel patency was achieved in 66\% at a median 19 months post-revision for all repair types. There was no difference in patency by the type of channel being revised, but there was based on revision technique, with channel replacement and above the fascia repairs being more successful $(\mathrm{p}=0.046)$. Channel incontinence occurred in $40 \%$ and was moderate to severe in $12 \%$. The type of channel being revised was strongly associated $(p=0.003)$ with any postoperative channel incontinence. Surgical complications occurred in $29 \%$ of all revision procedures, although most were low-grade.

Conclusions: Surgical revision of continent catheterizable channels for channel obstruction can be performed with acceptable rates of durable patency and incontinence; however, the surgeon needs to have experience in complex urinary diversion and familiarity with a variety of surgical revision strategies. 


\section{Introduction:}

Continent catheterizable channels (CCCs) are effective in facilitating bladder emptying, maintaining body image, and enhancing continence in patients with conditions that compromise volitional voiding. ${ }^{1}$

CCCs are classified by the bowel segment used, and the continence mechanism created. Commonly used bowel segments for construction are the appendix (a.k.a. Mitrofanoff), small bowel (Yang-Monti or spiral Casale-Monti), and the ileal cecal segment. Two continence mechanisms are commonly used: (1) tunneled channels (as described by Mitrofanoff) that rely on a flap-valve of bladder wall and (2) ileocecal valve-dependent tapered terminal ileal channels. ${ }^{2}$ The latter incorporates a cecal augment, hence its description as the hemi-Indiana augment or the cutaneous catheterizable ileal cecocystoplasty.

Common complications with CCCs include channel incontinence and difficult catheterization. Difficult catheterization, the focus of this manuscript, can be due to: (1) skin level obstruction, known as stomal stenosis; (2) damage more proximal within the channel by a false passage or ischemia leading to channel obstruction; (3) diverticulum; (4) channel redundancy; or (5) parastomal hernia. For brevity in this manuscript, we often refer to all of these etiologies as channel stenosis, recognizing that all of these etiologies do not involve obstruction from fibrosis. Between $6-36 \%$ of channels will require intervention for stenosis ${ }^{4-10}$; the incidence varies by channel type (e.g. Mitrofanoff vs. Monti vs. tapered ileum) as well as patient factors. When conservative measures such as dilation fail, channel revision surgery may be necessary; however, little is known about the success rates of revision surgery, and what is known is only in children. Herein, we describe outcomes for revision surgery in adults with CCCs with difficulty catheterizing; we quantify the risk of incontinence and restenosis after revision, and describe our management algorithm.

\section{Methods}

After institutional review board approval, we retrospectively reviewed the charts of adults who underwent CCC revision or replacement from 2000 to 2014 for stomal stenosis, channel obstruction, or difficulty with catheterization. Participating institutions included three from the Neurogenic Bladder Research Group (NBRG): The Universities of Minnesota, Michigan and Utah, which all have dedicated fellowship-trained reconstructive urologists with busy adult neurogenic bladder practices and multi-disciplinary transitional medicine clinics. Where the patients were not captured in a reconstructive database, a billing code query was used for Current Procedural Terminology (CPT) codes 50727 (revision of urinary-cutaneous anastomosis), 50830 (urinary undiversion), and 50845 (Mitrofanoff procedure) in order to identify potential patients for inclusion in the study. We included adults $>18$ years old who underwent surgical revision in the operating room. For patients who underwent multiple channel revisions, each procedure was treated as a separate procedure to accurately study the durability of each revision. Excluded procedures included stomal dilations under anesthesia and resection of CCCs followed by conversion to incontinent conduits. 
Patients were grouped as having either a congenital or acquired etiology leading to the creation of their original CCC. CCCs were classified by type of bowel and construction method (Mitrofanoff, Monti, or tapered ileum). They were also classified by continence mechanism (tunneled or plicated ileocecal valve). Channel revisions were classified into the three following categories based on the level of the revision surgery (Fig. 1): (1) above the rectus fascia, (2) below the fascia, or (3) partial or complete channel replacement. "Above the fascia” repairs included Y-V plasty ${ }^{11}$ or skin advancement flap. "Below the fascia” revisions included any channel revision requiring a laparotomy but not channel replacement with a new bowel segment. These revisions generally included resection of the stenotic portion of the channel and either maturation of the healthy end as a new stoma, or rarely, an anastomotic repair of the channel. Of note, the surgical approach to patients with difficulty catheterizing as a result of channel redundancy is similar to those with stenosis, in that after a laparotomy the distal end is excised until the appropriate channel length is achieved and the new distal end is matured to the skin. The third category, channel replacement, involved resection and replacement of a segment or all of the channel with a new section of bowel.

The primary outcome of interest was channel patency defined as freedom from reoperation for channel obstruction. Secondary outcomes included channel continence and postoperative complications. Channel continence was defined as none, mild ( $\leq 1$ pad per day or rare instances when catheterization schedules weren't followed) and moderate to severe ( $\geq$ two pads per day or causing significant impact on quality of life). The post-operative complications were rated on the Clavien-Dindo scale. ${ }^{12,13}$

Statistical comparisons were made using the SPSS version 22 software. Pearson chisquared analysis was used to compare categorical variables and the Student's t-test for continuous variables, with statistical significance defined at $\mathrm{p}<0.05$.

\section{Results}

51 patients (age 18 to 82 years old; mean 45) were identified who met our inclusion criteria. There were no crossover patients between institutions and each patient had stoma revision surgery by only 1 reconstructive urologist per institution. There were 68 revisions performed in 51 patients - 22 men and 29 women. Procedures were equally represented from each institution: University of Minnesota ( $n=23)$, University of Utah ( $n=17)$, and University of Michigan ( $n=28)$.

The etiology of bladder pathology leading to the creation of the CCC was equally divided between congenital (49\%) and acquired (51\%) conditions. Overall, spina bifida was the most prevalent etiology $(\mathrm{N}=20,29 \%)$. Spinal cord injury was present in $11(16 \%)$, cerebral palsy in 6 (9\%), bladder cancer in $7(10 \%)$, and 2 (3\%) patients had radiation as their primary etiology of bladder dysfunction. The mean interval between CCC and revision surgery was 4.6 years.

The original CCC was a Mitrofanoff in 19 (28\%), Monti in 25 (37\%) and tapered ileal limb in 24 (35\%). Revision approaches included 29 (43\%) above the fascia, 21 (31\%) below the fascia, and 18 (26\%) channel replacements. Revision approach differed by channel type 
( $p=0.003$, Table 1 ), most notable for the fact that no tapered ileal limbs needed channel replacement.

When stratified by congenital vs. acquired etiology, patients with congenital etiology accounted for most of the below fascia and channel replacement revisions $(p=0.019)$. Similarly, mean age at revision was associated with the type of revision $(\mathrm{p}=0.031)$ : 53 years for above the fascia, 41 years for below the fascia and 37 years for channel replacement (Table 1).

Channel patency was achieved in 66\% at a median 19 months (range 0.5-81 months) post-revision follow-up for all repair types. Above the fascia procedures were successful in $62 \%$, below the fascia in $52 \%$, and channel replacement in $89 \%$ of patients $(\mathrm{p}=0.046)$. There was no difference in patency by the type of channel being revised: Mitrofanoff patency was 74\% $(\mathrm{N}=14)$, Monti was 68\% ( $\mathrm{N}=17)$ and tapered ileum was $58 \%(\mathrm{~N}=14)$ after revision (Table 2). No significant relationships were found between success and age, etiology of primary channel creation, complications, or incontinence.

Overall, any degree of new incontinence occurred in $40 \%$ and moderate to severe incontinence in $12 \%$. The type of channel being revised was strongly associated $(\mathrm{p}=0.003)$ with any post-operative channel incontinence. Mitrofanoff, Monti, and tapered ileum had incontinence rates of 37\%, 64\%, and 17\% (Table 3). Type of revision strategy was not statistically significantly associated with incontinence - above the fascia, below the fascia, and channel replacements had 31\%, 33\%, and 61\% incontinence rates $\mathrm{p}=0.0948$ (Table 3).

Surgical complications occurred in 20/68 (29\%) revision surgeries, of which, four were Clavien $\geq 2$. Half of all grade 1 complications occurred in patients undergoing channel replacement $(\mathrm{p}<0.05): 8 / 16(50 \%)$.

\section{Discussion}

Herein we demonstrate that surgical revision of CCCs is successful in 66\% of patients at 1.5 years of follow-up. Further, we show that of all obstructed CCC in this cohort, tapered ileum channels had a lower likelihood of needing channel replacement, compared to Mitrofanoff or Monti channels. All channel revision types had good success, with a trend toward higher success (89\%) with channel replacement. Surgeons should interpret these findings to mean that one can pursue an above/below fascia revision when feasible because reasonable success rates can be expected. However, when a channel cannot be salvaged, channel replacement provides a more invasive but successful solution. In high volume centers, these surgical revisions/replacements can be accomplished with few complications (Clavien-Dindo $\geq 2$ in 6\%) and a low rate of new, severe incontinence (12\%).

The rates of surgical revision for CCC stomal/channel stenosis have been described mostly in children. Two of the largest pediatric series note revision rates of $11.7 \%$ and $24 \%$. Among 144 adults, Wiesner et al reported 17\% revision rate for stomal stenosis; the mean time to stenosis was 43.8 months. ${ }^{6}$ Redshaw et al in a study of 61 adult patients with cutaneous catheterizable ileal cecocystoplasty found only 3-13\% stenosis rate with a relatively short follow- 
up of 16 months. ${ }^{4}$ Durability of these reconstructions is unknown. But, all of these series speak to the success rate of an original CCC, not the success rate of revision surgery.

In our multi-institutional cohort of CCC revisions, 66\% of channels were still patent and free from repeat revision at a median of 19 months. Success was significantly higher after channel replacement surgery $(89 \% \mathrm{~N}=16)$ than after above fascia $(62 \% \mathrm{~N}=18)$ or below fascia repairs $(52 \%, \mathrm{~N}=10)$. There was no difference in success by the type of channel being revised. This represents the largest series of channel revision surgeries in the adult or pediatric literature. Compared to our study, Thomas et al (9) describe an 8\% failure rate among 25 children undergoing Mitrofanoff or Malone antegrade continence enema stoma revision. Whittam et al ${ }^{15}$ report a $16.6 \%$ revision rate for below the fascia repairs, of which, indications were difficulty catheterizing due to angulation in $8.4 \%$, stenosis in $4.1 \%$, and incontinence in $3.4 \%$. Of their revisions, $12.8 \%$ required a secondary revision. McAndrew et al $^{16}$ report a $50 \%$ failure rate of revision surgery for channel stenosis among 18 children with Mitrofanoffs or Malone antegrade continence enema stomas.

We found a significant relationship between Monti channels undergoing revision and new post-operative incontinence. After revision, 64\% ( $\mathrm{N}=16)$ of Monti revisions experienced some incontinence versus only $37 \%$ of Mitrofanoff and $17 \%$ of Tapered Ileum channels $(p=0.003)$. Most of this incontinence was mild, with only $12 \%$ of patients leaking $>1$ pad per day. Because Monti and Mitrofanoff tubes utilize the same tunneled continence mechanism, it is unclear why the continence rates would differ. In adults we typically can only use the appendix for a Mitrofanoff in the most ideal cases - thin abdominal wall and good capacity bladder. It is possible that the Monti channels had a higher rate of incontinence because they were more complex patients or the mesentery of the Monti tube prevented adequate tunneling compared to the appendix. The lower rate of incontinence in the tapered ileal channels may be reflective of their unique continence mechanism or the fact that $81 \%$ of these were present as part of a continent pouch rather than a bladder augmentation. Post-operative incontinence is a significant concern, especially in patients who use a wheelchair and at high risk for decubitus ulcers. Unfortunately, we did not have complete information on patients' pre-operative incontinence -most patients who underwent revision surgery presented with indwelling catheters, rendering assessment of pre-operative continence difficult. The indwelling catheter may have also compromised the continence mechanism. Although intraoperative measures such as initiating a cough or performing Crede in a full bladder facilitates assessing the degree of incontinence, this evaluation may not accurately reflect the risk of post-operative continence. In contrast to our results, McAndrews et al reported a 97\% continence rate for Mitrofanoff revisions in their pediatric series. ${ }^{16}$ Children differ significant from adults in terms of abdominal girth and fascial integrity, which may, in part, help explain our results. Additionally, their series were limited to patients with procedures utilizing the appendix. Whittam el al, in a series of Monti and spiral Monti revisions, describe a 3.4\% rate of incontinence following primary revisions and 50\% rate 
of incontinence following secondary revisions. ${ }^{15}$ Our rates of significant incontinence were low (12\%).

Surgical complications were common at 29\%, although Clavien grade $>=2$ complications were rare (6\%) and there were no complications higher than Clavien grade 3 . The low rate of major complications is similar to or lower than that found in the literature. ${ }^{17,18}$

It is worth noting that not all patients with channel obstruction require surgery. In fact, we attempt to manage many patients medically before resulting to surgical reconstruction. Given the lack of direction in the literature for managing these complex patients, we propose a management algorithm for adults with difficulty catheterizing a CCC; this is informed by our surgical and non-surgical experience (Fig. 2). In patients without a patent urethra, inability to catheterize a CCC requires emergent intervention. In those with a patent urethra, a urethral catheter can be placed acutely. An over-distended bladder will often kink the channel or close the continence mechanism; so we always re-attempt CCC catheterization after urethral Foley decompression. If the CCC catheterization is not successful after urethral catheter placement, then re-establishment of channel patency should, in our opinion, be pursued within a week or so in order to avoid completely losing the channel lumen. First attempts at the bedside may involve gentle catheterization with smaller catheters and hydrophilic guidewires. Early attempts at endoscopy with a pediatric cystoscope/ureteroscope should be performed if there is concern for trauma to the channel as perforation and false passage can lead to intra-abdominal complications. With the proper path confirmed and a wire in place, dilations up to the natural size of the channel can be performed safely. A safe method is to use a series of catheters converted to Council tip catheters by cutting the tip off; unsafe methods include balloon dilation and dilation by Van Buren or Goodwin sounds. Welk et al advocated application of a steroid ointment as a lubricant for 6 weeks after leaving the post-dilation catheter in place for $2-3$ weeks. ${ }^{10}$ Our practice is to leave a catheter in place for 2 weeks followed by resumption of intermittent catheterization and overnight usage of an L-stent to maintain patency if obstruction is at the skin level. ${ }^{19}$ The L-stent is especially useful in patients who need temporizing management until surgical revision, or are poor surgical candidates, or in those who are functioning well with it in place between catheterizations.

Several limitations in this study deserve mention. First, these data were collected retrospectively. Second, clinical outcomes and our management algorithm were created post hoc by consensus opinion; surgeons were free to choose the appropriate surgical management option at the time of surgery and were not guided by a study protocol or care algorithm. Finally, some of the details of prior conservative management techniques were not available and so are not presented herein. Also, we defined channel patency as freedom from reoperation for channel stenosis. Some patients will have re-stenosis that is managed non-operatively; if we were to include them our failure rates would be higher. We excluded non-operative management because it is an ill-defined outcome; for instance, we have some patients who use an indwelling catheter in their channel at night for convenience and others who use an indwelling catheter at night in 
order to dilate the channel. Separating these two scenarios apart from each other would often be inaccurate, so we elected to use surgical revision as our outcome. Finally, the heterogeneity of underlying etiology of bladder dysfunction in our patients, as well as the varied types of bladder and catheterizable channel construction weakens comparisons between the groups and the conclusions from this paper. However, the rarity of patients undergoing advanced urologic reconstruction does not allow narrowing of the patient population to report meaningful results.

\section{Conclusion}

Difficulty catheterizing a CCC can be addressed with surgical revision when non-surgical management fails. After surgical revision patients have acceptable rates of durable patency with few complications and low rates of incontinence. However, the surgeon needs experience in complex urinary diversion and familiarity with a variety of surgical revision strategies. Those with congenital neuropathic bladder and Mitrofanoff/Monti channels undergo more complex revisions/replacements. 


\section{References}

1. Horowitz M, KUHR C, MITCHELL M. Pediatric Urology: The Mitrofanoff Catheterizable ChannelPatient Acceptance. J Urol. 1995;153(3):771-772. doi:10.1016/S0022-5347(01)67715-2.

2. Castellan MA, Gosalbez R Jr, Labbie A, Monti PR. Clinical applications of the monti procedure as a continent catheterizable stoma. Urology. 1999;54(1):152-156. doi:10.1016/S0090-4295(99)00046-1.

3. Sarosdy MF. Continent urinary diversion using cutaneous ileocecocystoplasty. Urology. 1992;40(2):102-106. doi:10.1016/0090-4295(92)90503-O.

4. Redshaw JD, Elliott SP, Rosenstein DI, et al. Procedures Needed to Maintain Functionality of Adult Continent Catheterizable Channels: A Comparison of Continent Cutaneous Ileal Cecocystoplasty with Tunneled Catheterizable Channels. J Urol. 2014;192(3):821-826. doi:10.1016/j.juro.2014.03.088.

5. Leslie B, Lorenzo AJ, Moore K, Farhat WA, Bägli DJ, Pippi Salle JL. Long-Term Followup and Time to Event Outcome Analysis of Continent Catheterizable Channels. $J$ Urol. 2011;185(6):2298-2302. doi:10.1016/j.juro.2011.02.601.

6. Wiesner C, Stein R, Pahernik S, Hähn K, Melchior SW, Thüroff JW. Long-Term Followup of the Intussuscepted Ileal Nipple and the In Situ, Submucosally Embedded Appendix as Continence Mechanisms of Continent Urinary Diversion With the Cutaneous Ileocecal Pouch (Mainz Pouch I). J Urol. 2006;176(1):155-160. doi:10.1016/S00225347(06)00571-4.

7. Khavari R, Fletcher SG, Liu J, Boone TB. A Modification to Augmentation Cystoplasty With Catheterizable Stoma for Neurogenic Patients: Technique and Long-term Results. Urology. 2012;80(2):460-465. doi:10.1016/j.urology.2012.03.038.

8. HARRIS CF, COOPER CS, HUTCHESON JC, SNYDER HM III. APPENDICOVESICOSTOMY: THE MITROFANOFF PROCEDURE-A 15-YEAR PERSPECTIVE. J Urol. 2000;163(6):1922-1926. doi:10.1016/S0022-5347(05)67599-4.

9. Thomas JC, Dietrich MS, Trusler L, et al. Continent Catheterizable Channels and the Timing of Their Complications. J Urol. 2006;176(4):1816-1820. doi:10.1016/S00225347(06)00610-0.

10. Welk BK, Afshar K, Rapoport D, MacNeily AE. Complications of the Catheterizable Channel Following Continent Urinary Diversion: Their Nature and Timing. J Urol. 2008;180(4):1856-1860. doi:10.1016/j.juro.2008.03.093.

11. Chessa PP, Nicolosi A, Malloci A, Collu L, Tarquini A. [Y-V plasty for the treatment of stenosis of cutaneous stomas]. Minerva Chir. 1990;45(1-2):45-46.

12. Morgan M, Smith N, Thomas K, Murphy DG. IS CLAVIEN THE NEW STANDARD FOR REPORTING UROLOGICAL COMPLICATIONS? BJU International. 2009;104(4):434-436. doi:10.1111/j.1464-410X.2009.08516.x. 
13. Clavien PA, Barkun J, de Oliveira ML, et al. The Clavien-Dindo Classification of Surgical Complications. Annals of Surgery. 2009;250(2):187-196.

doi:10.1097/SLA.0b013e3181b13ca2.

14. Szymanski KM, Whittam B, Misseri R, et al. Long-term outcomes of catheterizable continent urinary channels: What do you use, where you put it, and does it matter? Journal of Pediatric Urology. 2015;11(4):210.e1-210.e7. doi:10.1016/j.jpurol.2015.05.002.

15. Whittam BM, Szymanski KM, Flack C, et al. A comparison of the Monti and spiral Monti procedures: A long-term analysis. Journal of Pediatric Urology. 2015;11(3):134.e1134.e6. doi:10.1016/j.jpurol.2014.12.013.

16. McAndrew HF, Malone PSJ. Continent catheterizable conduits: which stoma, which conduit and which reservoir? BJU International. 2002;89(1):86-89. doi:10.1046/j.14644096.2001.01828.x.

17. Rapoport D, Secord S, MacNeily AE. The challenge of pediatric continent urinary diversion. Journal of Pediatric Surgery. 2006;41(6):1113-1117.

doi:10.1016/j.jpedsurg.2006.02.006.

18. Rubenwolf PC, Beissert A, Gerharz EW, Riedmiller H. 15 years of continent urinary diversion and enterocystoplasty in children and adolescents: the Würzburg experience. BJU International. 2010;105(5):698-705. doi:10.1111/j.1464-410X.2009.08908.x.

19. Mickelson JJ, Yerkes EB, Meyer T, Kropp BP, Cheng EY. L Stent for Stomal Stenosis in Catheterizable Channels. J Urol. 2009;182(4):1786-1791. doi:10.1016/j.juro.2009.02.068. 


\section{Figures and Tables}

Fig. 1. Levels of obstruction and treatment options for difficult to catheterize continent channels.

\begin{tabular}{|c|c|c|}
\hline Level of repair & Description & \\
\hline $\begin{array}{l}\text { Above the } \\
\text { fascia }\end{array}$ & & $\begin{array}{l}\text { Peri-stomal incision } \\
\text { Dissection to fascia through peri- } \\
\text { stomal fat } \\
\text { Incision through stenotic portion of } \\
\text { channel } \\
\text { V flap creation } \\
\text { Apex of spatulated channel sutured to } \\
\text { tip of "V" with 4-0 Vicryl } \\
\text { Remaining stomal edges sutured to } \\
\text { skin edges with 4-0 Vicryl }\end{array}$ \\
\hline $\begin{array}{l}\text { Below the } \\
\text { fascia }\end{array}$ & & $\begin{array}{l}\text { Mobilization of stoma below fascia } \\
\text { Mature healthy, proximal portion of } \\
\text { channel as new stoma }\end{array}$ \\
\hline $\begin{array}{l}\text { Subtotal or } \\
\text { total channel } \\
\text { replacement }\end{array}$ & & $\begin{array}{l}\text { - Intact continence mechanism: } \\
\text { - Remove offending segment of } \\
\text { channel } \\
\text { - Harvest new bowel segment and } \\
\text { add to stomal end } \\
\text { - Compromised continence mechanism } \\
\text { - New tunneled channel } \\
\text { Cutaneous catheterizable ileal } \\
\text { cecocystoplasty }\end{array}$ \\
\hline
\end{tabular}


Fig. 2. Stepwise approach in managing difficult to catheterize continent channels.

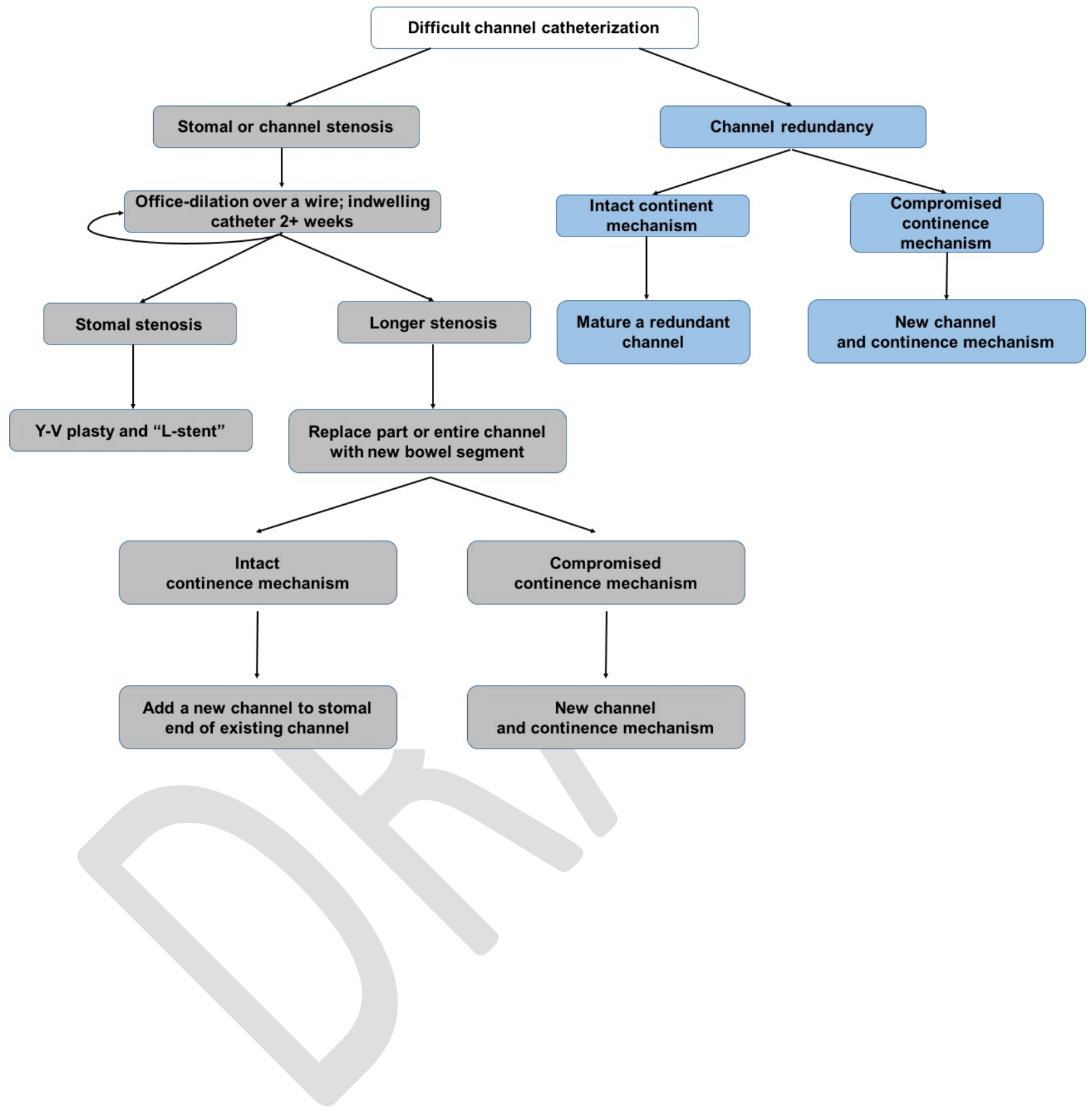




\begin{tabular}{|c|c|c|c|c|c|}
\hline Variable & Cohort & $\begin{array}{l}\text { Above } \\
\text { fascia }\end{array}$ & $\begin{array}{l}\text { Below } \\
\text { fascia }\end{array}$ & $\begin{array}{c}\text { Channel } \\
\text { replacement }\end{array}$ & $\mathbf{p}$ \\
\hline \multicolumn{6}{|l|}{ Sex } \\
\hline Male & $29(43 \%)$ & $13(45 \%)$ & $\begin{array}{c}9 \\
(43 \%)\end{array}$ & $\begin{array}{c}7 \\
(39 \%)\end{array}$ & 0.93 \\
\hline Female & $39(57 \%)$ & $16(55 \%)$ & $12(57 \%)$ & $\begin{array}{c}11 \\
(61 \%)\end{array}$ & \\
\hline Age at revision (years) & 45 & 53 & 41 & 37.3 & 0.031 \\
\hline $\mathrm{n}(\%)<30$ & $17(25 \%)$ & $\begin{array}{c}4 \\
(14 \%) \\
\end{array}$ & $\begin{array}{c}7 \\
(33 \%) \\
\end{array}$ & $\begin{array}{c}6 \\
(33 \%) \\
\end{array}$ & \\
\hline $30-49$ & $26(38 \%)$ & $\begin{array}{c}8 \\
(28 \%) \\
\end{array}$ & $10(48 \%)$ & $\begin{array}{c}8 \\
(44 \%)\end{array}$ & \\
\hline$\geq 50$ & $25(37 \%)$ & $17(59 \%)$ & $\begin{array}{c}4 \\
(19 \%) \\
\end{array}$ & $\begin{array}{c}4 \\
(22 \%)\end{array}$ & \\
\hline Institution & & +2 & 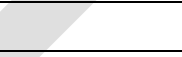 & 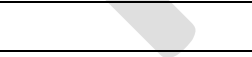 & \\
\hline Minnesota & $23(34 \%)$ & $\begin{array}{c}5 \\
(17 \%) \\
\end{array}$ & $\begin{array}{c}7 \\
(33 \%) \\
\end{array}$ & $\begin{array}{c}11 \\
(61 \%) \\
\end{array}$ & $0.033^{*}$ \\
\hline Michigan & $28(41 \%)$ & $16(55 \%)$ & $\begin{array}{c}9 \\
(43 \%) \\
\end{array}$ & $\begin{array}{c}3 \\
(17 \%) \\
\end{array}$ & \\
\hline Utah & 17 (25\%) & $\begin{array}{c}8 \\
(28 \%) \\
\end{array}$ & $\begin{array}{c}5 \\
(24 \%) \\
\end{array}$ & $\begin{array}{c}4 \\
(22 \%)\end{array}$ & \\
\hline Etiology & & & & & $0.019^{*}$ \\
\hline Congenital & 33 (49\%) & $\begin{array}{c}9 \\
(31 \%)\end{array}$ & $15(71 \%)$ & $\begin{array}{c}9 \\
(50 \%)\end{array}$ & \\
\hline Acquired & 35 (51\%) & $20(69 \%)$ & $\begin{array}{c}6 \\
(29 \%) \\
\end{array}$ & $\begin{array}{c}9 \\
(50 \%) \\
\end{array}$ & \\
\hline Type of channel modified & & & & & 0.003 \\
\hline $\begin{array}{r}\text { Mitrofanoff } \\
\text { Column \% } \\
\text { Row \% } \\
\end{array}$ & $\begin{array}{c}19 \\
28 \% \\
\mathrm{n} / \mathrm{a} \\
\end{array}$ & $\begin{array}{c}5 \\
17 \% \\
26 \% \\
\end{array}$ & $\begin{array}{c}7 \\
33 \% \\
37 \% \\
\end{array}$ & $\begin{array}{c}7 \\
39 \% \\
37 \% \\
\end{array}$ & \\
\hline $\begin{array}{r}\text { Monti } \\
\text { Column \% } \\
\text { Row \% } \\
\end{array}$ & $\begin{array}{c}25 \\
37 \% \\
\mathrm{n} / \mathrm{a} \\
\end{array}$ & $\begin{array}{c}8 \\
28 \% \\
32 \% \\
\end{array}$ & $\begin{array}{c}6 \\
29 \% \\
24 \% \\
\end{array}$ & $\begin{array}{c}11 \\
61 \% \\
44 \% \\
\end{array}$ & \\
\hline $\begin{array}{r}\text { Tapered ileum } \\
\text { Column \% } \\
\text { Row \% } \\
\end{array}$ & $\begin{array}{c}24 \\
35 \% \\
\mathrm{n} / \mathrm{a} \\
\end{array}$ & $\begin{array}{c}16 \\
55 \% \\
67 \% \\
\end{array}$ & $\begin{array}{c}8 \\
38 \% \\
33 \% \\
\end{array}$ & $\begin{array}{l}0 \\
0 \\
0\end{array}$ & \\
\hline
\end{tabular}




\begin{tabular}{|c|c|c|c|}
\hline Variable & $\begin{array}{c}\text { Success } \\
45 / 68(66 \%)\end{array}$ & $\begin{array}{c}\text { Failure } \\
\text { 23/68 (34\%) }\end{array}$ & $\mathbf{p}$ \\
\hline Age & & & 0.39 \\
\hline$<30$ & $12(71 \%)$ & $5(29 \%)$ & \\
\hline $30-49$ & $19(73 \%)$ & $7(27 \%)$ & \\
\hline$\geq 50$ & $14(56 \%)$ & $11(44 \%)$ & \\
\hline Gender & & & 0.68 \\
\hline Male & $20(69 \%)$ & $9(31 \%)$ & 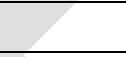 \\
\hline Female & $25(64 \%)$ & $14(36 \%)$ & \\
\hline Etiology & & & 0.26 \\
\hline Congenital & $21(64 \%)$ & $12(36 \%)$ & \\
\hline Acquired & $24(69 \%)$ & $11(31 \%)$ & \\
\hline $\begin{array}{l}\text { Type of channel } \\
\text { modified }\end{array}$ & & & 0.56 \\
\hline Mitrofanoff & $14(74 \%)$ & $5(26 \%)$ & 7 \\
\hline Monti & $17(68 \%)$ & $8(32 \%)$ & \\
\hline Tapered ileum & $14(58 \%)$ & $10(42 \%)$ & \\
\hline Type of revision & & & $0.046^{*}$ \\
\hline Above fascia & $18(62 \%)$ & $11(38 \%)$ & +2 \\
\hline Below fascia & $11(52 \%)$ & $10(48 \%)$ & \\
\hline Channel replacement & $16(89 \%)$ & $2(11 \%)$ & 8 \\
\hline Complications & & & 0.89 \\
\hline None & $32(67 \%)$ & $16(33 \%)$ & \\
\hline Clavien 1 & $10(63 \%)$ & $6(38 \%)$ & \\
\hline$\geq$ Clavien 2 & $375 \%)$ & $1(25 \%)$ & \\
\hline $\begin{array}{l}\text { Degree of } \\
\text { incontinence }\end{array}$ & & +3 & 0.84 \\
\hline None & $27(66 \%)$ & $14(34 \%)$ & \\
\hline Mild & $12(63 \%)$ & $7(37 \%)$ & \\
\hline Moderate to severe & $6(75 \%)$ & $2(25 \%)$ & \\
\hline
\end{tabular}




\begin{tabular}{|c|c|c|c|}
\hline Variable & $\begin{array}{c}\text { No incontinence } \\
41 / 68(60 \%) \\
\end{array}$ & $\begin{array}{c}\text { Any incontinence } \\
27 / 68(40 \%)\end{array}$ & $\mathbf{p}$ \\
\hline \multicolumn{4}{|l|}{ Age } \\
\hline$<30$ & $9(53 \%)$ & $8(47 \%)$ & 0.76 \\
\hline $30-49$ & $16(62 \%)$ & $10(39 \%)$ & \\
\hline$\geq 50$ & $16(64 \%)$ & $9(36 \%)$ & \\
\hline \multicolumn{4}{|l|}{ Gender } \\
\hline Male & $21(72 \%)$ & $8(28 \%)$ & 0.08 \\
\hline Female & $20(51 \%)$ & $19(49 \%)$ & \\
\hline Etiology & & 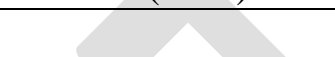 & \\
\hline Congenital & $19(58 \%)$ & $14(42 \%)$ & 0.66 \\
\hline Acquired & $22(63 \%)$ & $13(37 \%)$ & \\
\hline \multicolumn{4}{|l|}{$\begin{array}{l}\text { Type of channel } \\
\text { modified }\end{array}$} \\
\hline Mitrofanoff & 12 (63\%) & $7(37 \%)$ & \\
\hline Monti & $9(36 \%)$ & $16(64 \%)$ & 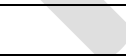 \\
\hline Tapered ileum & $20(83 \%)$ & $4(17 \%)$ & $0.003^{*}$ \\
\hline \multicolumn{4}{|l|}{ Type of revision } \\
\hline Above fascia & $20(69 \%)$ & $9(31 \%)$ & 0.095 \\
\hline Below fascia & $14(67 \%)$ & $7(33 \%)$ & \\
\hline Channel replacement & $7(39 \%)$ & $11(61 \%)$ & \\
\hline \multicolumn{4}{|l|}{ Complications } \\
\hline None & $32(67 \%)$ & $16(33 \%)$ & 0.24 \\
\hline Clavien 1 & $7(44 \%)$ & $9(56 \%)$ & \\
\hline$\geq$ Clavien 2 & $2(50 \%)$ & $2(50 \%)$ & \\
\hline
\end{tabular}

